\title{
Parameters Effect the Behavior of Spandrel Beams
}

\author{
Anis A.Mohamad Ali, Rasha M.Salman \\ Departement of Civil Engineer, Basrah University
}

\begin{abstract}
This paper studies interaction response between the spandrel beam and floor beams with different floor beam properties using ANSYS14.0 nonlinear models. A threedimensional finite element models have been established to provide a numerical solution as an alternative theoretical approach with some acceptable accuracy. The calculated ultimate loads, torque and angel of twist are compared with the experimental observation of twenty two statically indeterminate spandrel-floor beams and very good agreement is observed. Parametric study are presented to clarify the effect of floor beam length to the spandrel beam length ratio, depth of the floor beam to spandrel beam ratio. Empirical expressions are presented.
\end{abstract}

Keywords - reinforced concrete Spandrel beams, floor beam, compatibility torsion, ANSYS 14.0.

\section{Introduction}

Spanderl beams are very command members in many building frames. Such members are subjected to twisting about its longitudinal axial, known as torsion, in addition to the shearing force and bending moment, hence the external loads act far away from the vertical plane of bending. Torsion may be classified in to two main types ${ }^{[1]}$ : the first type is called equilibrium or statically determinate torsion at which the torsional moment cannot be reduced by the redistribution of internal forces. It develops when the external load has no alternative load path but must be supported by torsion. For such cases, the torsion required to maintain static equilibrium and prevent collapse of the structure. Figure 1(a) shows an example of torsion to maintain equilibrium on bridge deck. The second type is called compatibility or statically indeterminate torsion in which torsional moment can be reduced by redistribution of internal forces generated by twisting. This type generates in primary structures beams supporting secondary beams for example, the torsion developed in to spandrel beams of a building caused by loading from a cast in place slab, and equal to the negative moment in the slab. Figure 1 (b) shows the torsion due to rotation. In this type, the torsional stiffness of the spandrel beam must be considered. This loading mechanism develops torsional forces that are transferred to columns. Several method of analysis $(2,3,4)$ have been developed in order to obtain an economic design. Earlier researches presented by Collins and Lampert, 1973, (2) show that the design procedures could be simplified if zero torsional stiffness is assumed and only minimum torsional reinforcement is required in order to ensure the ductility and the limit crack width. Hsu and Burton(3),1974, Based on the elastic stiffness analysis, the torsional moment distribution to spandrel beam at the joint is calculated according to Eq.(1).

$$
M=\frac{\frac{3}{16} P \ell_{f}}{1+\frac{3}{4} \frac{K_{f}}{K_{u}}}
$$

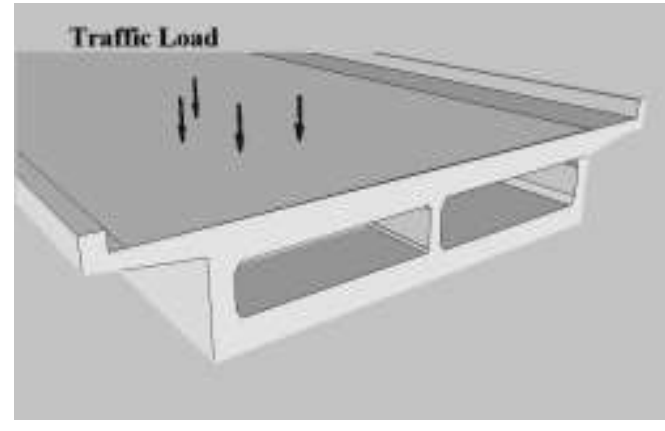

(a)Torsion due to traffic load

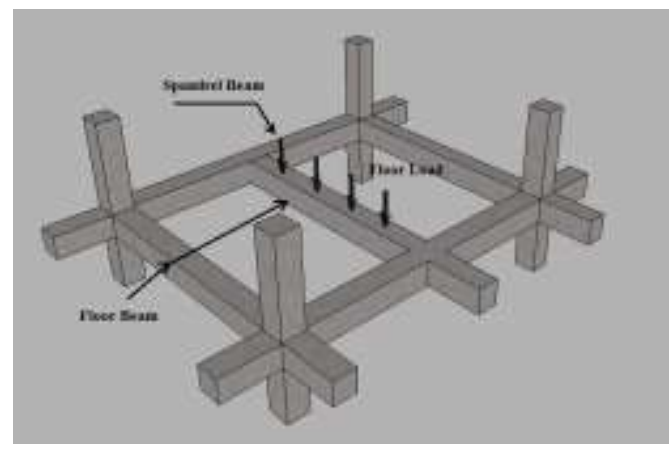

(b)Torsion at joint due to rotation

Fig.1 Examples of torsion in reinforced concrete frame; (a) equilibrium torsion(b) compatibility torsion.

Abul Mansur and Rangan (4), concluded that the use of the conventional elastic method based on the gross stiffness is uneconomic and the steel remains under stressed.

Despite the rigorous studies on spandrel beams, there have been few empirical and semi-empirical formulas for expressing the relation between the spandrel and floor beam with different floor beam properties therefore excessive studies should be carried out to satisfy the above target.

In the current study a three-dimensional finite element models are presented to give accurate simulation for geometry, loading condition and locations of reinforcement bars. Design recommendations with empirical expressions formulas are presented to express the effects of floor beams length, depth on overall behavior of the spandrel beams.

\section{Objective and Scope}

Effectiveness of any finite element model requires a confidence in the accuracy and the reliability of the model. Validation of any model may be achieved by comparing numerical results with available experimental data. Several numerical tests are required to ensure the validity of the numerical models ${ }^{[9]}$. Suitable finite element models that 
represent the concrete and the steel reinforcement have been selected to predict the overall behavior of the tested beams.

In the present study numerical tests using ANSYS 14.0 program, are carried out on twenty two experimental spandrel-floor beams subjected to concentrated load at the mid span of the floor beam.

Design recommendations with empirical expressions formulas are presented. In order to validate finite element models a comparison between numerical results and available experimental data has been achieved.

\section{Finite Element Simulation and ANSYS14.0 Software}

The finite element analysis is a reliable and usable means for analyzing of civil structures with the availability of concrete technology ${ }^{[5]}$. It is an approximate numerical method that can make a realistic representation of reinforced concrete and take into account the actual complexity of the construction. In this approach, the actual continuum is replaced by an equivalent idealized structure composed of discretized elements connected together at a finite number of nodes. Each one is analyzed by considering the deformations that occur in that region of the structure. Variation of displacement across the element is assumed; hence, the displacement at any point within the element can be related to the nodal placements, simple functions are chosen to express these relations. Then by integrating over the domain, the strain and kinetic energies of the element are obtained in terms of nodal variables.

The global stiffness matrix can be derived by combining the individual stiffness matrices of all elements in a proper manner and applying conditions of equilibrium at every node of the idealized structure.

ANSYS14.0 software is used to simulate the experimental spandrel -floor beams subjected to concentrated load. It has much finite element analysis capabilities ranging from a simple linear static analysis to complex nonlinear transient dynamic analysis. There are two methods to use ANSYS14.0, the graphical user interface GUI and the command file. In this study the GUI method of ANSYS14.0 was used to simulate the required beams. It is clear that the success of the analytical simulation depends on the suitable selection of elements type and number, proper material models, suitable boundary condition simulation, convergence criteria and solution method.

There are three main steps required to simulate any model in ANSYS program which are: Preprocessing, solution and the post processing steps. The preprocessor software engine is used to define the element types, element real constant, material properties and model geometry. Application of load and boundary conditions are applied by solution part. Finally, at post processing step checking evaluation and presentation of the analytical results will accrued in an efficient envelops and contour plots.

Modeling and meshing geometry of tested beams can be simplified by the following sequence steps:

1. Simulate the concrete, steel plate and lever arms volumes in the similar dimension as the full scale tested beams taking in to account the benefit of the glue command presented in prepressing step of ANSYS14.0 program to connects the elements as shown in Fig. (2).

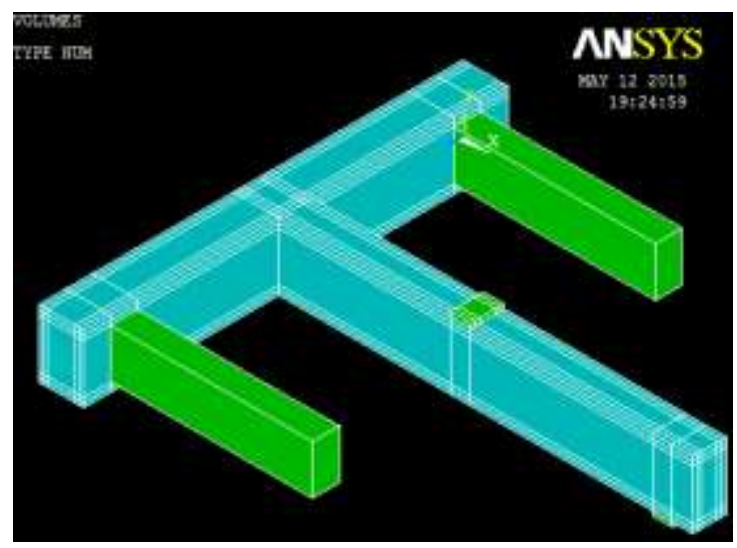

Fig.2 Volume Representation

2. Meshing each volume individually with observation the suitable aspect ratio for each element as shown in Fig. (3). Convergence study towards validating adequacy of the adopted discretization, is performed ,by doubling the number of elements and comparing results, until the difference in results is insignificant and no further refinement is necessary

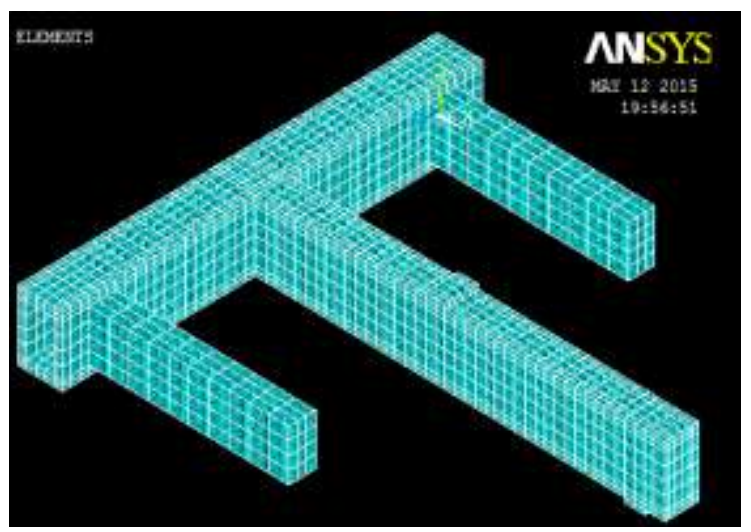

Fig.3 Volume Meshing

3. Simulate of longitudinal and stirrup steel bars for spandrel and floor beam according to their actual location in the experimental beams. Both concrete and steel material sharing the same points to provide perfect bond between them taking the advantage of merge nodes option to collect separate entities that have the same location into a single one Fig.(4) shows longitudinal and stirrups representation of beam GRA2[8] as an example of reinforcement steel simulation. 


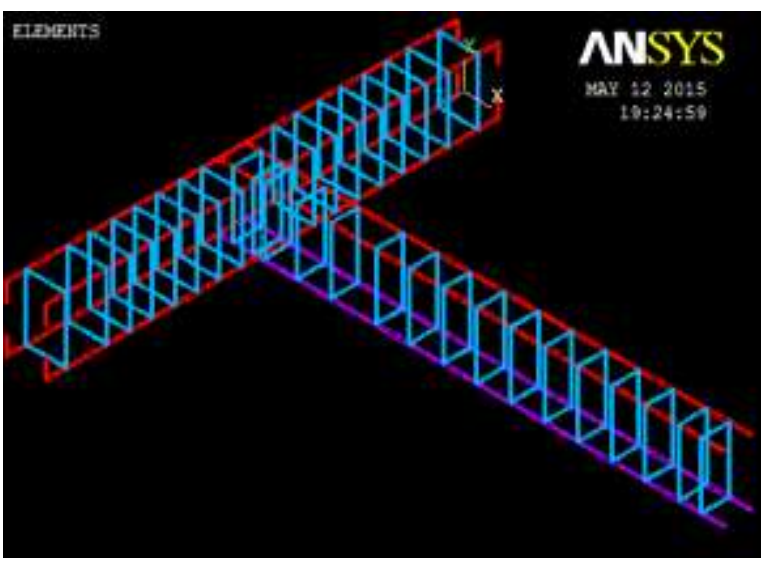

Fig.4 Steel Simulation

\section{Element Types Used In the Model}

The ANSYS14.0 element library contains more than 100 different element types[ ]. Each element type has a unique number and prefix that identifies the element category. Table 1 shows the type of elements used to analyze experimental spandrel-floor beams.

\section{Table 1 Element Type}

\begin{tabular}{|c|c|c|}
\hline $\begin{array}{l}\text { Ele. } \\
\text { No. }\end{array}$ & $\begin{array}{l}\text { Element } \\
\text { Type }\end{array}$ & Representation \\
\hline 1 & Solid 65 & $\begin{array}{c}\text { Concrete Spandrel and Floor } \\
\text { Beams }\end{array}$ \\
\hline 2 & Link180 & $\begin{array}{c}\text { Longitudinal Steel Reinforcement } \\
\text { Positive (variables) }\end{array}$ \\
\hline 3 & Link180 & $\begin{array}{c}\text { Longitudinal steel reinforcement } \\
\text { Negative (variables) }\end{array}$ \\
\hline 4 & Link180 & Stirrups (variables) \\
\hline 5 & Solid185 & Steel arms and plates \\
\hline
\end{tabular}

\section{Material Properties}

Material number one refers to properties of solid65 element linear and multi-linear isotropic material properties were adopted. The linear isotropic properties were defined by modulus of elasticity, Ex, and possions ratio. The experimental values of Ex, and an assumed possions ratio 0.2 were adopted into analysis. The multi-linear isotropic depends on the Von Mises failure criteria along Willam and Warnke. The multi-linear isotropic stress-strain curve of concrete was obtained from the following equations:

$$
\begin{gathered}
\varepsilon_{o}=\frac{2 f_{c}^{\prime}}{E_{c}} \\
E=\frac{f}{\varepsilon} \\
f=\frac{E_{c} \varepsilon}{1+\left(\frac{\varepsilon}{\varepsilon_{o}}\right)^{2}}
\end{gathered}
$$

Where $(f)$ is the stress at any strain $\varepsilon,(\varepsilon)$ is the strain of concrete, $\left(\varepsilon_{O}\right)_{\text {is }}$ the strain at ultimate compressive strength $^{f_{c}^{\prime}}$, and $(E)$ is the tangent modulus of elasticity. As shown in Fig. (4), point one defined as $\left(0.25 f_{c}^{\prime}\right)$ and calculated by Hooks law Eq. (3) since it is within the linear range of stress-strain curve. The intermediate nodes were calculated using Eq. (4).

The last point represents the stress at which crushing strain of concrete take place $\left(\varepsilon_{u}=0.003 \mathrm{~mm} / \mathrm{mm}\right)$. The concrete density $(2400 \mathrm{~kg} / \mathrm{m} 3)$ has been considered in order to include the self-weigh of the beams. The concrete properties data expressed in terms of constants range from 1 to 7 .

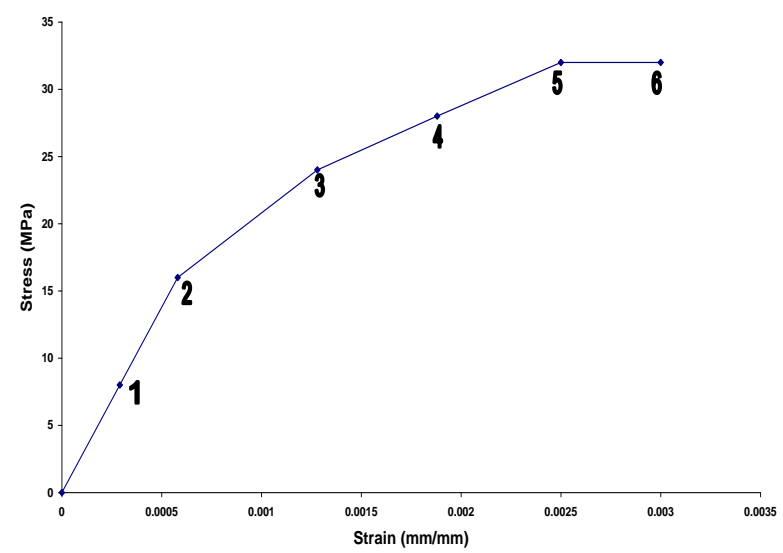

Fig. (5) Stress - Strain Curve for Concrete.

Constant 1,2 are two shear transfer coefficients, one for open cracks and the other for closed cracks, were used to consider the retention of shear stiffness in cracked concrete taking in to the account the interaction of rebar and concrete in order to simulate load transfer across cracks through the rebar. These coefficients range from $(0.0)$ which represent the smooth cracks to (1.0) represents complete loss of shear transfer. In the present study values of 0.5 , and 0.9 are used for Constant 1, 2 which give more accurate analytical results. The experimental tensile and compressive strength of concrete were described as constant3,4 respectively. Absence of data removes the cracking and crushing capability, while giving a value of (-1) for constant 3 , or 4 removes the cracking and crushing capability, respectively. If constants 1 to 4 are input and constants 5 to 8 are deleted, the latter constants take default values. If any one of constants 5 to 8 is input, there is no default and all 8 constants must be input. 


\section{Validation of Numerical Results}

Typical section spandrel-floor beam is presented in fig (6).The experimental beams properties and details are listed in table (2) .Test results are used for the verification of the numerical models. The ultimate load capacities, ultimate torque, angle of twist of the numerical models are compared with the experimental results as shown in table (2). It has shown that good agreement has been achieved.

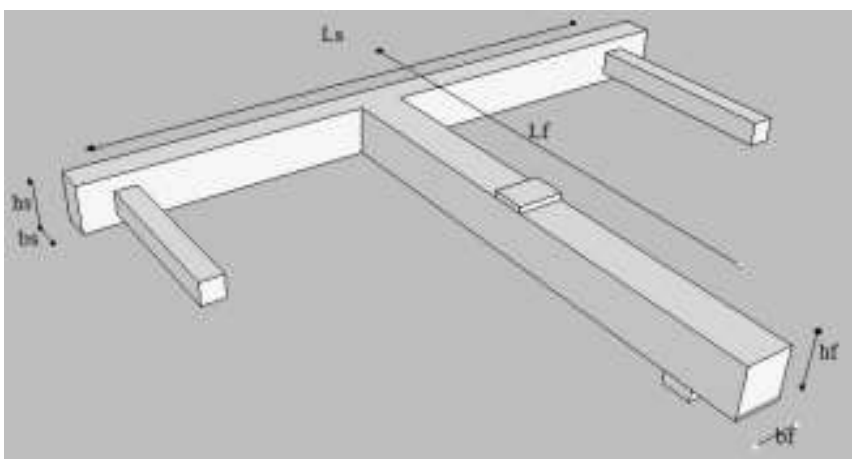

Fig. (6) Typical section of spandrel-floor beam

\section{Effects of Floor Beam Length to Spandrel Beam Length Ratio (Lf/Ls)}

The Floor beam length to spandrel beam length ratio is much important in controlling the maximum response of type of loading.

As shown in Fig. (7), five floor to spandrel beams ratios $0.75,1,1.5,2$ and 2.5 are considered to study the spandrel response. It can be noticed that when the ratio Lf/Ls increase, ultimate load, ultimate torque and angle of twist increase until it reaches to value of lf/ls equal to about 1.0 after that decreasing values can be noticed as the ratio reaches to the 3.0.Sudden failure occurs at floor beam when the ratio becomes closer to 3.0 since maximum floor beam deflection occurred due to heavy weight of the floor beam. Angle of twist are increased as the ratio of Lf/Ls increase. Empirical expressions are presented to express the relation between the ultimate load, ultimate torque, maximum deflections and angle of twist with $\mathrm{Lf} / \mathrm{Ls}$ ratios.

Table 2 Comparison of Experimental and ANSYS Results

\begin{tabular}{|c|c|c|c|c|c|c|c|c|c|c|c|c|c|c|c|c|c|c|}
\hline \multirow{3}{*}{$\begin{array}{c}\text { Investig } \\
\text { ator }\end{array}$} & \multirow{3}{*}{$\begin{array}{l}\text { Spec } \\
\text { GR- }\end{array}$} & \multicolumn{3}{|c|}{ Spandrel beam } & \multicolumn{3}{|c|}{ Floor beam } & \multirow{3}{*}{$\begin{array}{c}f_{c}^{\prime} \\
\mathrm{MPa}\end{array}$} & \multirow{3}{*}{$\begin{array}{l}E c \\
\text { GPa }\end{array}$} & \multirow{2}{*}{\multicolumn{2}{|c|}{$\begin{array}{c}\text { Ultimate } \\
\text { load }\end{array}$}} & \multirow{3}{*}{$\begin{array}{l}\text { Pan } \\
\text { Pex }\end{array}$} & \multirow{2}{*}{\multicolumn{2}{|c|}{$\begin{array}{l}\text { Ultimate } \\
\text { Torque }\end{array}$}} & \multirow{3}{*}{$\frac{\text { Tans }}{\text { Texp }}$} & \multirow{2}{*}{\multicolumn{2}{|c|}{$\begin{array}{c}\text { Angule of } \\
\text { Twist } \\
(\text { Rad/m) } \\
\text { x10 }^{-3} \\
\end{array}$}} & \multirow{3}{*}{$\frac{\overline{\text { Gan }}}{\text { Өex }}$} \\
\hline & & \multirow[t]{2}{*}{$\begin{array}{c}\mathrm{Ls} \\
\mathrm{m}\end{array}$} & \multirow[t]{2}{*}{$\begin{array}{c}\mathrm{bs} \\
\mathrm{mm}\end{array}$} & \multirow[t]{2}{*}{$\begin{array}{c}\mathrm{hs} \\
\mathrm{mm}\end{array}$} & \multirow[t]{2}{*}{$\begin{array}{l}\mathrm{Lf} \\
\mathrm{m}\end{array}$} & \multirow[t]{2}{*}{$\begin{array}{c}\mathrm{bf} \\
\mathrm{mm}\end{array}$} & \multirow[t]{2}{*}{$\begin{array}{c}\mathrm{hf} \\
\mathrm{mm}\end{array}$} & & & & & & & & & & & \\
\hline & & & & & & & & & & Pex & Pan & & Tex & Tan & & $\overline{\theta e}$ & $\mathbf{\theta a}$ & \\
\hline \multirow{8}{*}{ Jawad[6] } & B1 & 1.2 & 120 & 300 & 1.6 & 120 & 180 & 32.8 & 30.6 & 82.8 & 85.0 & 1.03 & 2.70 & 2.66 & 1.00 & 24 & 23 & 0.95 \\
\hline & $\mathrm{C} 1$ & 1.2 & 120 & 300 & 1.6 & 120 & 180 & 30.6 & 29.8 & 74.4 & 75.0 & 1.00 & 3.97 & 3.20 & 0.81 & 30 & 28 & 0.93 \\
\hline & D1 & 1.2 & 120 & 300 & 1.6 & 120 & 180 & 34.5 & 32.9 & 111 & 112 & 1.01 & 2.90 & 3.00 & 1.03 & 20 & 14 & 0.70 \\
\hline & $\mathrm{C} 3$ & 1.8 & 120 & 300 & 1.8 & 120 & 180 & 28.6 & 28.3 & 65.2 & 67.5 & 1.03 & 2.60 & 2.53 & 0.72 & 20 & 14 & 0.7 \\
\hline & D3 & 1.8 & 120 & 300 & 1.8 & 120 & 180 & 42.8 & 33.1 & 73.6 & 75.0 & 1.01 & 2.93 & 3.55 & 1.21 & 27 & 23 & 0.85 \\
\hline & E1 & 1.2 & 120 & 300 & 1.6 & 120 & 180 & 28.6 & 28.3 & 90.0 & 92.0 & 1.02 & 3.2 & 2.63 & 0.81 & 27 & 20 & 0.74 \\
\hline & E2 & 1.2 & 120 & 300 & 1.6 & 120 & 180 & 29.3 & 28.9 & 81.0 & 66.0 & 0.81 & 3.2 & 3.8 & 0.75 & 27 & 21 & 0.77 \\
\hline & E3 & 1.8 & 120 & 300 & 1.8 & 120 & 180 & 30.2 & 29.6 & 98.0 & 95.0 & 0.97 & 2.9 & 3.2 & 0.75 & 12 & 9.0 & 0.75 \\
\hline \multirow{5}{*}{$\begin{array}{c}\text { Muherde } \\
\text { en [7] }\end{array}$} & A2 & 1.5 & 120 & 300 & 1.5 & 120 & 300 & 30.3 & 29.6 & 95.2 & 74.0 & 0.78 & 1.80 & 2.1 & 0.4 & 10 & 4.2 & 0.42 \\
\hline & D1 & 1.5 & 120 & 300 & 1.5 & 120 & 300 & 20.0 & 25.8 & 81.4 & 80.0 & 0.99 & 1.61 & 1.9 & 0.56 & 9.7 & 5.4 & 0.55 \\
\hline & D2 & 1.5 & 120 & 300 & 1.5 & 120 & 300 & 40.0 & 33.0 & 90.7 & 90.7 & 1.00 & 1.90 & 2.3 & 0.97 & 7.2 & 7.0 & 0.79 \\
\hline & E1 & 1.5 & 160 & 300 & 1.5 & 120 & 300 & 23.0 & 28.0 & 90.0 & 95.0 & 1.05 & 2.30 & 1.8 & 0.78 & 8.0 & & \\
\hline & F3 & 1.5 & 160 & 300 & 1.5 & 120 & 300 & 30.0 & 29.5 & 100 & 110 & 0.11 & 4.45 & 3.20 & 0.72 & 12 & & \\
\hline \multirow{8}{*}{$\operatorname{Easa}^{[8]}$} & $\mathrm{A} 2$ & 1.5 & 200 & 300 & 1.7 & 150 & 300 & 26.9 & 26.2 & 110 & 110 & 1.00 & 7.58 & 6.30 & 0.83 & 32 & 25.0 & 0.78 \\
\hline & B1 & 1.8 & 200 & 300 & 1.7 & 150 & 300 & 25.7 & 28.2 & 103 & 80.3 & 0.79 & 3.25 & 2.89 & 0.89 & 34 & 26.0 & 0.76 \\
\hline & B2 & 1.5 & 200 & 300 & 1.7 & 150 & 300 & 25.3 & 27.2 & 105 & 110 & 1.05 & 3.60 & 3.35 & 0.93 & 32 & 27.0 & 0.84 \\
\hline & $\mathrm{C} 1$ & 1.5 & 200 & 300 & 1.7 & 150 & 300 & 28.5 & 28.1 & 120 & 96 & 0.80 & 9.08 & 8.58 & 0.94 & 33 & 26.0 & 0.78 \\
\hline & $\mathrm{C} 2$ & 1.5 & 200 & 300 & 1.7 & 150 & 300 & 26.7 & 27.6 & 110 & 110 & 1.00 & 6.13 & 5.32 & 0.87 & 34 & 32.0 & 0.94 \\
\hline & C3 & 1.5 & 200 & 300 & 1.7 & 150 & 300 & 26.5 & 26.5 & 110 & 97.0 & 0.88 & 5.10 & 3.53 & 0.70 & 33 & 22.0 & 0.66 \\
\hline & E1 & 1.5 & 200 & 300 & 1.7 & 150 & 300 & 17.1 & 20.7 & 110 & 109 & 0.99 & 6.20 & 4.33 & 0.70 & 27 & 28.0 & 1.03 \\
\hline & E2 & 1.5 & 200 & 300 & 1.7 & 150 & 300 & 33.5 & 32.9 & 110 & 113 & 1.03 & 8.60 & 7.42 & 0.86 & 27 & 19.0 & 0.70 \\
\hline $\begin{array}{c}\text { Abul } \\
\text { Mansur } \\
\text { and } \\
\text { Rangan } \\
{[4]}\end{array}$ & SA3 & 3.0 & 180 & 300 & 3.0 & 180 & 300 & 40.2 & & 138 & 138 & 1.00 & 6.6 & 5.4 & 0.82 & $\begin{array}{c}13 . \\
5\end{array}$ & 11.2 & 0.83 \\
\hline
\end{tabular}



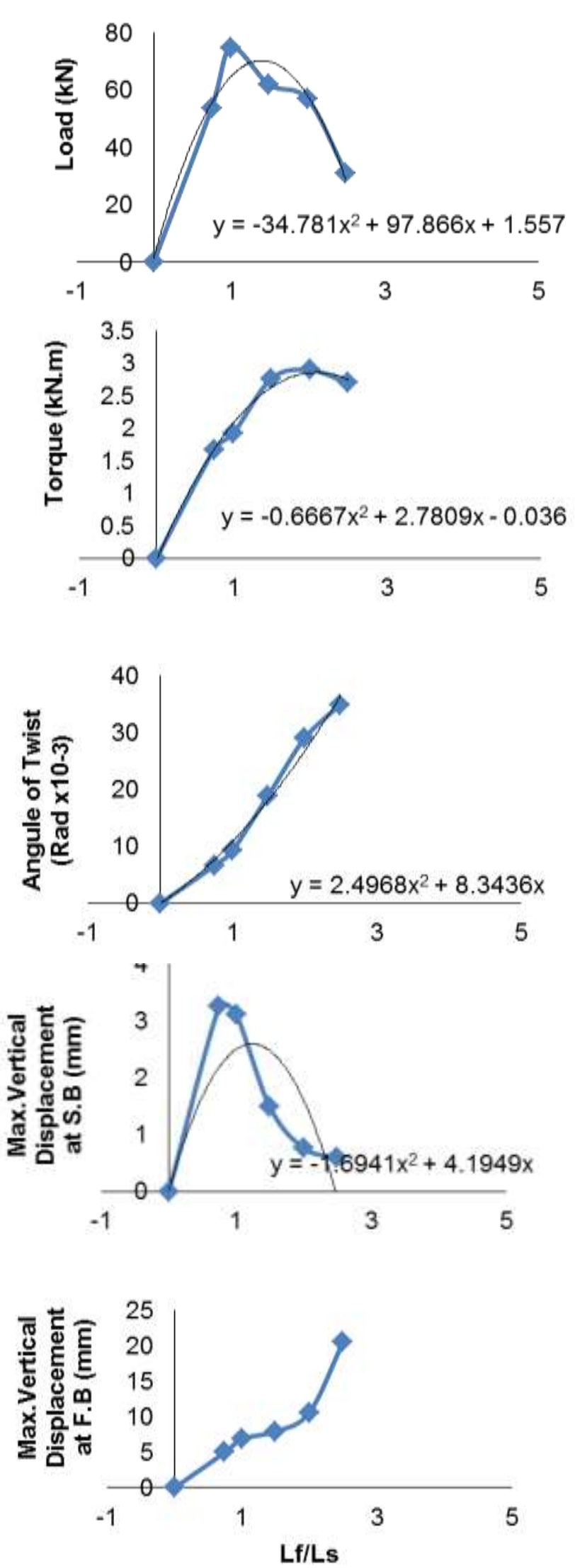

Fig. (7) Effect of Floor Beam Length to Spandrel Beam Length Ratio (Lf/Ls)

\section{Effect of Floor Beam Depth to Spandrel Beam Depth Ratio (hf/hs)}

As shown in Fig. (7), four floors to spandrel beams depth ratios $(0.5,0.6,0.75$ and 1.0$)$ are studied to investigate the spandrel response to the variation of the floor beam depth .All details and properties of the section and materials are the same. It can be noticed that ultimate load and the angle of twist increase as hf/hs increase. Critical design ratio of $\mathrm{hf} / \mathrm{hs}$ is about 0.6 where maximum deflections at the mid span of the floor beam and at the joints occurred. Minimum floor and spandrel beam deflections sight when the floor beam and the spandrel beams have the same height. 
Proc. of the Third Intl. Conf. Advances in Civil, Structural and Mechanical Engineering- CSM 2015

Copyright (C) Institute of Research Engineers and Doctors, USA .All rights reserved. ISBN: 978-1-63248-062-0 doi: 10.15224/ 978-1-63248-062-0-81
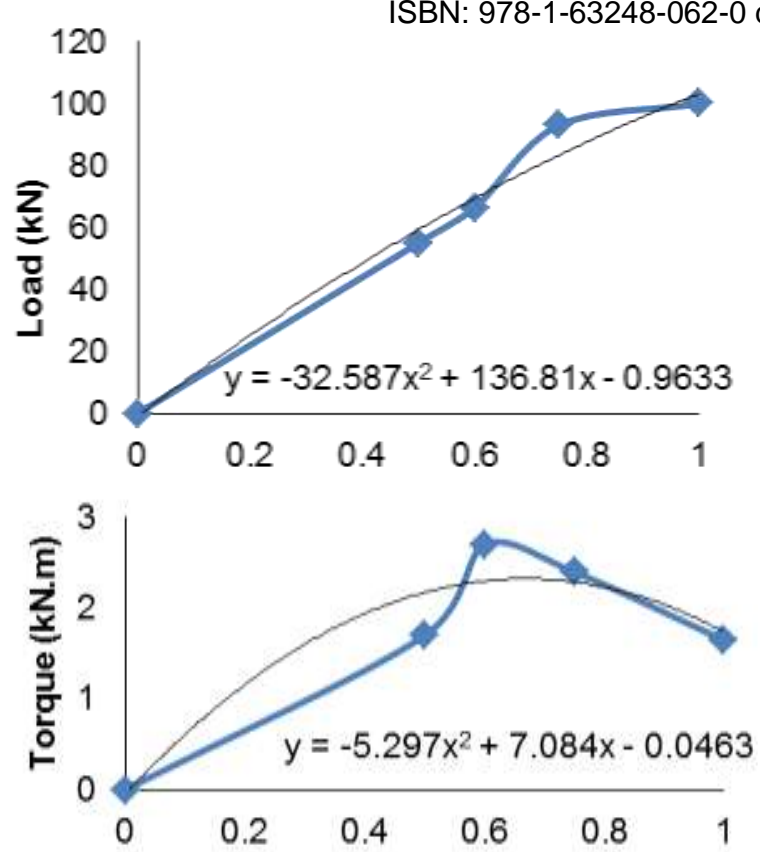

References

1. American Concrete Institute "Report on Torsion in Structural Concrete,AC1 445.1R12 " reported by ACI-ASCE Committee 445, April 2013.

2. Collins and Lampert "Redistribution of moments at cracking-The Key to simpler torsion design" Analysis of structural systems for torsion, ACI publications, Sp35, Detroit, 1973.

3. Hsu, T.T.C. and Burton, K.T. " Design of reinforced concrete spandrel beam" Journal of the structural Division, proc. of the ASCE,Vol.100,ST 1, January 1974,pp.209229.

4. Abul Mansure, M.and Rangan, B.V. “ Torsion in spandrel beams "Journal of the structural Division, proc. of the ASCE,Vol.104,ST 7, July 1978,pp.1061-1075.

5. Rao, S. S., "The Finite Element Method In Engineering.", Printed In Great Britain A.Wheaton and Co.Ltd.,Exeter,1982.

6. Jawad, N.A.M. "Strength and Behaviour of Reinforced Concrete Spandrel Beam” ,Msc. Thesis, College of Engineering, University of Basrah,1988

7. Muherdeen, E. H., "Failure Surface of Reinforced Concrete Spandrel Beams", M.Sc. Thesis, College of Engineering, University of Basrah,1991.

8. Esaa, J ., "Strength and Behavior of Reinforced Concrete Hollow Spandrel Beams",M.Sc. Thesis, College of Engineering, University of Basrah,1992.

9. Mohamad Ali, A. A., "Strength and Behaviour of Reinforced Concrete Spandrel Beams", $\mathrm{PhD}$. Thesis, University of Edinburgh. 1983.

Fig. (8) Effect of Floor Beam Depth to Spandrel Beam Depth Ratio (hf/hs) 